\title{
Regression analysis for determination of antioxidant activity of coconut sap under various heating temperature and concentration of lysine addition
}

\author{
${ }^{1, *}$ Sulistyo, S.B. and ${ }^{2}$ Haryanti, P. \\ ${ }^{1}$ Agricultural Engineering Study Program, Faculty of Agriculture, Jenderal Soedirman University, \\ Purwokerto, Indonesia \\ ${ }^{2}$ Food Technology Study Program, Faculty of Agriculture, Jenderal Soedirman University, Purwokerto, \\ Indonesia
}

\author{
Article history: \\ Received: 11 December 2019 \\ Received in revised form: 28 \\ January 2020 \\ Accepted: 31 January 2020 \\ Available Online: 20 \\ February 2020
}

Keywords:

Browning,

Maillard reaction,

Amino acid,

Total phenolic content,

Scavenging activity

DOI:

https://doi.org/10.26656/fr.2017.4(4).410

\begin{abstract}
This research aimed to determine the antioxidant activity of coconut sap added by different concentration of lysine during the heating process by means of regression analysis. This regression can be utilized to predict the antioxidant activity of coconut sap. A number of antioxidant parameters, i.e. total phenolic content, browning intensity, DPPH scavenging activity, and chelating activity, were measured using standard methods. The results showed that the changes in the total phenolic content of coconut sap against temperature during heating process followed a logarithmic regression function. The correlation between total phenolic content and heating temperature was quite strong until the temperature reached $100^{\circ} \mathrm{C}$. Moreover, the changes in both browning intensity and DPPH scavenging activity of coconut sap against heating temperature followed an exponential regression. A quadratic regression function can represent the relationship between the chelating activity of coconut sap and heating temperature since the correlation of those parameters was relatively strong in the temperature range of $28-100^{\circ} \mathrm{C}$. This study showed that the changes in total phenolic content, browning intensity, DPPH scavenging activity, and chelating activity of coconut sap during heating can be determined using regression analysis.
\end{abstract}

\section{Introduction}

Coconut sap is sugary exudates, sweet, oyster-white color and translucent, with nearly neutral $\mathrm{pH}$ that is obtained from the young inflorescence of a coconut tree (Cocos nucifera L.) (Borse et al., 2007). Coconut sap can be processed to beverage or as a raw material of coconut sugar. Because of its nutritious, coconut sap will suffer spontaneous fermentation and become alcoholic and acidic due to microbial activity (Hariharan et al., 2014). Granulated coconut sugar is produced from coconut sap through a lengthy heating process. The typical attribute of coconut sugar quality is the brown color that occurs during the heating process of the coconut sap. The brown color occurred during the heating of the sap is caused by Maillard reaction. This reaction is important in the production of sugar i.e. its impact to the flavor, color, and aroma (Asikin et al., 2014).

Maillard reaction intensity is commonly influenced by the composition of reactants, i.e. reducing sugar and amino acids contained in sap (Nagai et al., 2018), as well as the temperature of the heating process (Carciochi et al., 2016). According to Ho et al. (2008), reactant such as free amino acids are important as source of amino groups, free ammonia or nitrogen atoms through both deamination and retro-aldol reactions, while monosaccharide such as glucose and fructose play a role in the initial Maillard reaction by forming an abundant pool of high reactive $\mathrm{C} 2, \mathrm{C} 2$ and $\mathrm{C} 4$ dicarbonyl compounds.

The addition of lysine provided more basic amino groups, so the Maillard reaction occurred at the alkaline $\mathrm{pH}$ created the products via the 2.3-enolization track via 1-deoxy-2,3-dicarbonyl. This route will produce reductone compound that has antioxidant activity. Therefore, it is important to know the change of chemical and antioxidant properties of coconut sap induced with lysine which generated Maillard reaction products and melanoidin on the granulated coconut sugar. The Maillard reaction products and melanoidin were contributed to the antioxidant activity of granulated coconut sugar.

Wijewickreme et al. (1999) reported that the amino 
acid and reducing sugar in Maillard reaction were contributed to food color, flavor and antioxidant. In vitro studies, showed that MRPs may have antioxidant activity as they can role as metal chelators, radical scavengers (Kim, 2013). Yan et al. (2018) reported that MRPs derived from chitooligosaccharide and glycine model system exhibited strong antioxidant activity. The addition of this MRPs to fruit juices also increased the antioxidant capacity of these beverages. Karseno et al. (2018) stated that there was a significant correlation between the browning intensity and DPPH radical scavenging activity with a correlation coefficient (r) of 0.93 .

The objectives of this research were to analyze the antioxidant activity of coconut sap added with various concentration of lysine during the heating process by means of regression analysis.

\section{Materials and methods}

\subsection{Materials}

The coconut sap was tapped from spathes of tall variety of coconut trees (Cocos nucifera L.) cultivated in Sikapat Village, Sumbang District, Banyumas Regency, Central Java, Indonesia with the altitude of 500-1000 m above sea level. The tapping process was conducted during the daytime for 9 hours $(0600-1500)$ in fine weather with a temperature of $24-27^{\circ} \mathrm{C}$. The relative humidity ranged about $91-92 \%$.

Several chemicals, i.e. potassium hydrogen tartrate, phenol, sodium sulfite, sodium hydroxide, hydrochloric acid, D-glucose, ninhydrin, dipotassium hydrogen phosphate, potassium dihydrogen phosphate, stannous chloride, L-glutamic acid, ethanol, Folin Ciocalteu, sodium carbonate, ammonium thiocyanate, ferrous chloride and hydrochloric acid were purchased from Merck (Darmstadt, Germany). Ferrozine was procured from Fluka Chemical. Co. (Buchs, Switzerland) while 3,5-dinitrosalicylic acid and 2,2-diphenyl-1picrylhydrazyl were obtained from Sigma Chemical Co. (St. Louis, MO, USA).

\subsection{Collection of coconut sap}

The coconut sap was obtained from the tapped inflorescence of 15 coconut trees. The sap was collected into plastic containers which have been washed using hot water to minimize microbial contamination. The preservatives added were $1.7 \mathrm{~g} / \mathrm{L}$ lime with the addition of $0.56 \mathrm{~g} / \mathrm{L}$ of mangosteen peel powder. The procedure of the tapping process was as follows. The tip of the coconut inflorescence was cut by a sterilized stainless steel knife. A plastic container with the preservatives substance inside was placed covered up the cut inflorescence to collect the coconut sap. The coconut sap collected was measured the $\mathrm{pH}$ value and total soluble solids by a portable refractometer (Atago, Japan) immediately. The sap samples which their chemical properties meet the requirement for granulated coconut sugar production were then processed.

\subsection{Heating of coconut sap}

A $10 \mathrm{~L}$ of coconut sap was filtered with a filter cloth, then was divided into four parts. The first part was sap sample without addition of amino acid, the second, third and fourth part was added with $0.25,0.5$ and $0.75 \mathrm{mM}$ lysine, respectively. Each sap sample was poured into an aluminum pan and was subsequently heated by a gas stove. During the heating process, the sap sample was continuously agitated until the temperature of the sap reached $118^{\circ} \mathrm{C}$ (for about 50 mins). A $50 \mathrm{~g}$ of sap sample was collected at heating temperature of $40,60,80,100$ and $118^{\circ} \mathrm{C}$ for analyzing the antioxidant properties.

\subsection{Chemical analysis of coconut sap}

After the heating process of coconut sap, the next step was chemical analysis. Four antioxidant properties, i.e. total phenolic content (TPC), browning intensity, DPPH radical scavenging activity and chelating activity, were subsequently analyzed.

\subsubsection{Total phenolic}

The estimation of the total phenolic content of the coconut sap was performed according to the FolinCiocalteu method with slight modifications (Payet et al., 2005). A total of $30 \mu \mathrm{L}$ of the sample were added with $150 \mu \mathrm{L}$ of $10 \%$ Folin-Ciocalteu reagent in a test tube. After incubated for 8 mins, an amount of $120 \mu \mathrm{L}$ of $7.5 \%$ $\mathrm{Na} 2 \mathrm{CO} 3$ dissolved in distilled water must be added. The sample was then incubated for $1 \mathrm{hr}$ at $30^{\circ} \mathrm{C}$, and the absorbance at $765 \mathrm{~nm}$ was measured. For the blank measurement, the sample was replaced by an appropriate solvent which was subtracted from the absorbance at 765 $\mathrm{nm}$. The measurement result was then obtained by reporting the absorbance in the standard curve of gallic acid used as the standard phenolic compound. The results were expressed in milligrams of gallic acid equivalent per 100 gram of sample (mgGAE/100 g of sample).

\subsubsection{Browning intensity}

The browning color of coconut sap samples during the heating process was measured according to the method of Ajandouz et al. (2001) with slight modification. The sap samples were adjusted with distilled water $(1: 25 \mathrm{w} / \mathrm{v})$, then centrifuged at $1006 \mathrm{x} g$ for 15 mins. The absorbance of browning was measured 
using a Genesys 10S UV-Vis spectrophotometer (Thermo Scientific; Carlsbad, CA, USA) at $420 \mathrm{~nm}$, as an index of the brown polymers formed in more advanced stages.

\subsubsection{Radical scavenging activity}

DPPH radical scavenging activity of coconut sap was measured using the method of Payet et al. (2005). A volume of $280 \mu \mathrm{L}$ of $0.1 \mathrm{mM} \mathrm{DPPH} \cdot$ methanolic solution was pipetted into each tube test followed by 20 $\mu \mathrm{L}$ of sample, or solvent for the blank. The mixture was subsequently incubated at room temperature for 30 minutes, and the absorbance at $515 \mathrm{~nm}$ was then measured with a spectrophotometer. The antioxidant activity can be evaluated as a percentage of the radical scavenging activity (RSA) using the following equation:

$$
\operatorname{RSA}(\%)=(\text { Ao-As }) / \text { Ao } \times 100
$$

Where Ao is the absorbance of the blank and As is the absorbance of the sample at $515 \mathrm{~nm}$ after 30 mins.

\subsubsection{Chelating activity}

The ability of sap samples to chelate the metal ions $\mathrm{Fe}^{2+}$ was investigated according to Kim (2013). One gram of sap samples with 5-fold dilution was prepared, then filtered with filter paper to obtain sap solution. One hundred microliters of coconut sap solution were added with $600 \mu \mathrm{L}$ of distilled water and $100 \mu \mathrm{L}$ of $0.2 \mathrm{mM}$ $\mathrm{FeCl}_{2} \bullet 4 \mathrm{H}_{2} \mathrm{O}$. The mixture was allowed to rest at room temperature for $30 \mathrm{~s}$. The reaction mixture, which contained $100 \mu \mathrm{L}$ of distilled water instead of sample, was served as the control. The reaction mixture was then added with $200 \mu \mathrm{L}$ of $1 \mathrm{mM}$ ferrozine and its changes in color were monitored at $562 \mathrm{~nm}$ with a Genesys $10 \mathrm{~S} \mathrm{UV}$ -Vis spectrophotometer (Thermo Scientific; Carlsbad, CA, USA) after 10 mins of resting time at room temperature. The chelating activities were calculated using the following equation:

$$
\text { Chelation activity }(\%)=(\text { Ao-As }) / \text { Ao } \times 100
$$

Where Ao is the absorbance of the control and As is the absorbance of the sample after 10 mins incubation.

\section{Results and discussion}

\subsection{Regression analysis of total phenolic content (TPC)}

As seen in Figure 1, the mean total phenolic content for all concentration of lysine addition follows a logarithmic regression. According to our experiment, mean total phenolic content of coconut sap during heating tended to decrease and had a strong relationship with heating temperature $(T)$ from room temperature $\left(28^{\circ} \mathrm{C}\right)$ until $100^{\circ} \mathrm{C}$ with coefficient of determination $\left(R^{2}\right)$ value of 0.9764 and the mathematical expression between these parameters was $T P C=-0.104 \times \ln (T)+$ 0.7986. However, when the coconut sap was continuously heated until the temperature of $118^{\circ} \mathrm{C}$, the value of mean total phenolic content rose sharply. This increase might be caused by the breakdown of cellular constituents which release bound phenolic compounds from the ester bonds due to the thermal process ( $\mathrm{Ng}$ et al., 2020). The relationships between TPC and heating temperature for different concentration of lysine addition also followed logarithmic regression and tended to decrease, indicated by the negative coefficient of $\ln (T)$, for a certain range of heating time, as seen in Table 1 . The experiment results revealed that the addition of 0.75 $\mathrm{mM}$ lysine contributed to the highest increase of final TPC to the initial TPC. The addition of $0.75 \mathrm{mM}$ lysine escalated the TPC up to $167 \%$. On the other hand, based on the multiple linear regression results the combination of lysine concentration addition and the heating temperature had less significant effect on the changes of TPC during heating. This can be seen from the small adjusted $R^{2}$, i.e. 0.177 .

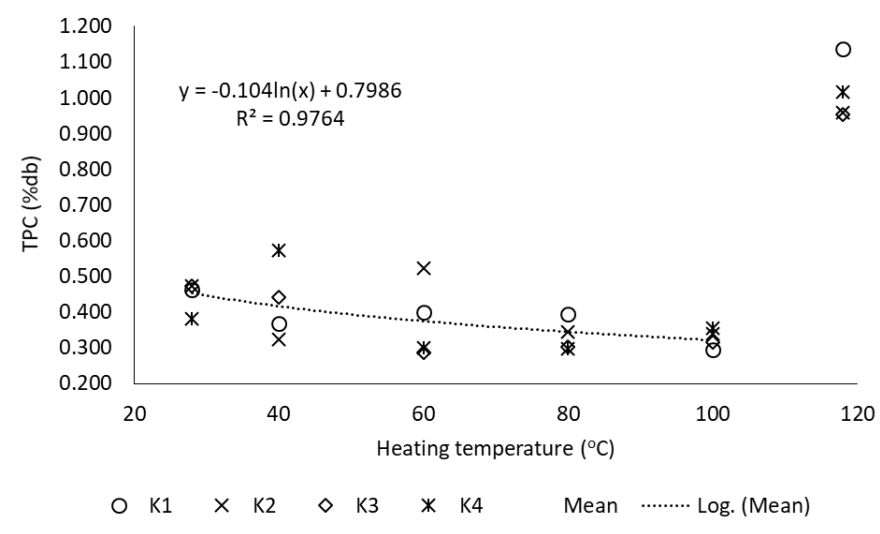

Figure 1. The relationship between heating temperature and TPC with various concentration of lysine addition.

\subsection{Regression analysis of browning intensity}

The relationship between the average of browning intensity $(B I)$ of sap during heating with various concentration of lysine addition and the heating temperature was relatively significant (Figure 2). The changes in browning intensity during heating followed an exponential regression function. According to our experiment, the changes of browning intensity can be expressed as $B I=0.013 \times \mathrm{e}^{0.0372 \times T}$ with $\mathrm{R}^{2}=0.7676$. Moreover, the changes of BI during heating in each concentration of lysine addition had the same pattern, i.e. exponential regression, as seen in Figure 3. In the heating process of coconut sap from room temperature to $80^{\circ} \mathrm{C}$ the browning intensity slightly increased, however, it escalated significantly when the heating temperature reached $100^{\circ} \mathrm{C}$ and keep increased considerably until $118^{\circ} \mathrm{C}$. Based on the experiments, the addition of 0.5 
Table 1. Regression equation of the relationship between TPC and heating temperature with various concentration of lysine addition

\begin{tabular}{cccc}
\hline Concentration of lysine addition $(\mathrm{mM})$ & Regression equation & $\mathrm{R}^{2}$ & Range of heating temperature $\left({ }^{\circ} \mathrm{C}\right)$ \\
\hline 0 & $\mathrm{TPC}=-0.091 \times \ln (\mathrm{T})+0.7501$ & 0.5982 & $28-100$ \\
0.25 & $\mathrm{TPC}=-0.068 \times \ln (\mathrm{T})+0.6717$ & 0.1469 & $28-100$ \\
0.5 & $\mathrm{TPC}=-0.147 \times \ln (\mathrm{T})+0.9563$ & 0.7746 & $28-100$ \\
0.75 & $\mathrm{TPC}=-0.245 \times \ln (\mathrm{T})+1.409$ & 0.5585 & $40-100$ \\
\hline
\end{tabular}

$\mathrm{mM}$ lysine presented the highest final browning intensity, i.e. around 42 times compared to the initial browning intensity, which was indicated by the absorbance of $420 \mathrm{~nm}$. The combination of lysine addition and heating temperature resulted in a fair correlation to the TPC with adjusted $\mathrm{R}^{2}$ of 0.56 .

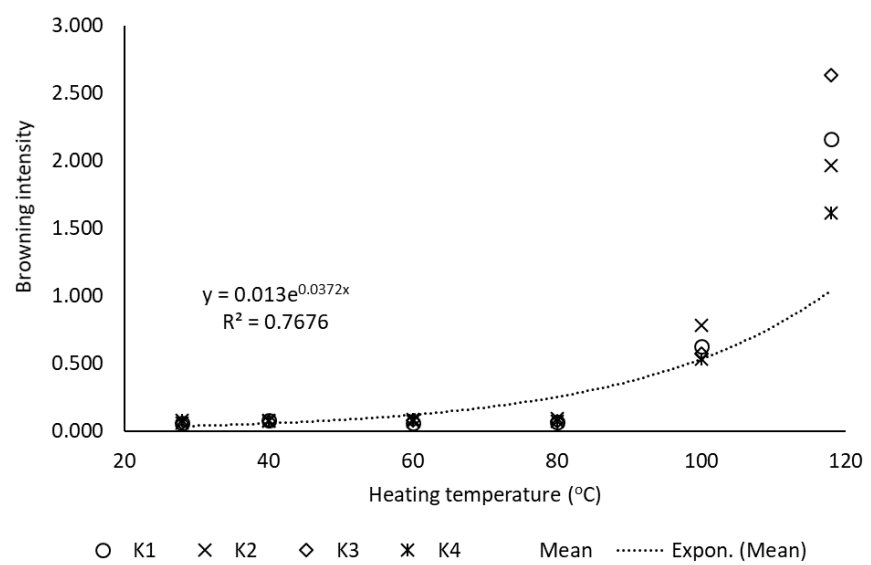

Figure 2. The relationship between heating temperature and browning intensity with various concentration of lysine addition.

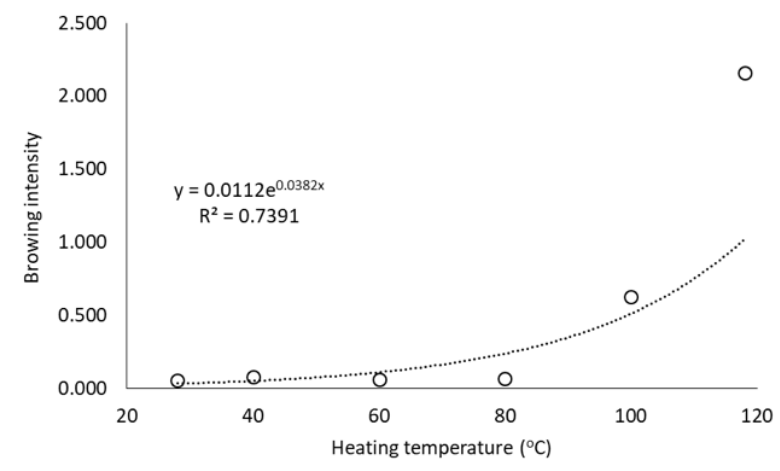

(a)

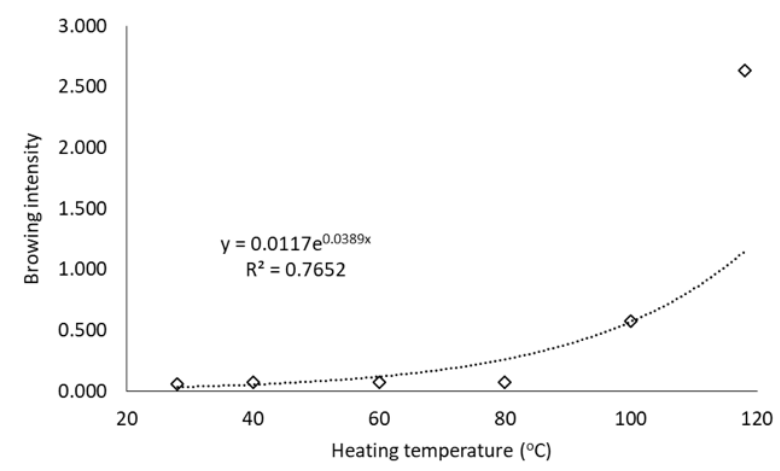

(c)

\subsection{Regression analysis of DPPH scavenging activity}

Figure 4 shows the relationship between mean DPPH scavenging activity and heating temperature of coconut sap with various lysine concentration added to the sap. The changes of DPPH scavenging activity followed an exponential regression with the mathematical expression of $D P P H=0.5884 \times \mathrm{e}^{0.0296(T)}$ and $\mathrm{R}^{2}$ of 0.5619 . As the same as browning intensity, DPPH scavenging activity of coconut sap slightly increased during heating from room temperature until the temperature of $100^{\circ} \mathrm{C}$ and subsequently escalated greatly at heating temperature of $118^{\circ} \mathrm{C}$. For each concentration of lysine addition, the changes of DPPH scavenging activity also followed the exponential regression function (Table 2). The addition of lysine to coconut sap gave a significant difference of final and initial DPPH $\left(\Delta_{\mathrm{DPPH}}\right)$. The higher the lysine concentration added, the smaller the DPPH difference. As seen in Table 3, the treatment of $\mathrm{K} 1$ (no lysine addition) provided the highest DPPH difference, i.e. 35 times of initial DPPH, which was calculated using the following formula:

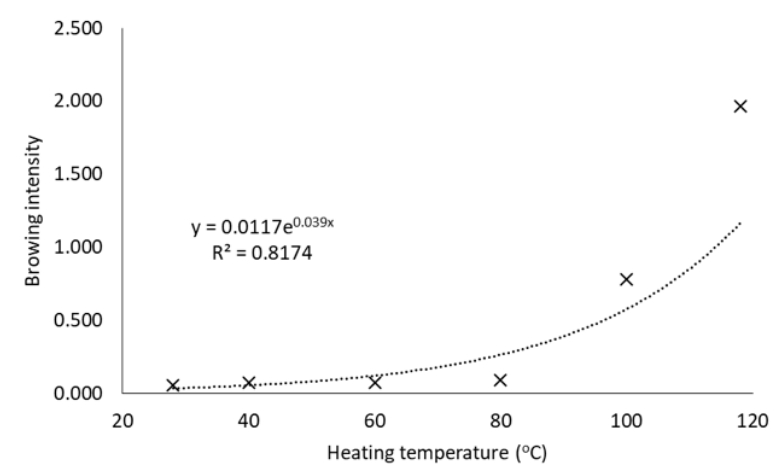

(b)

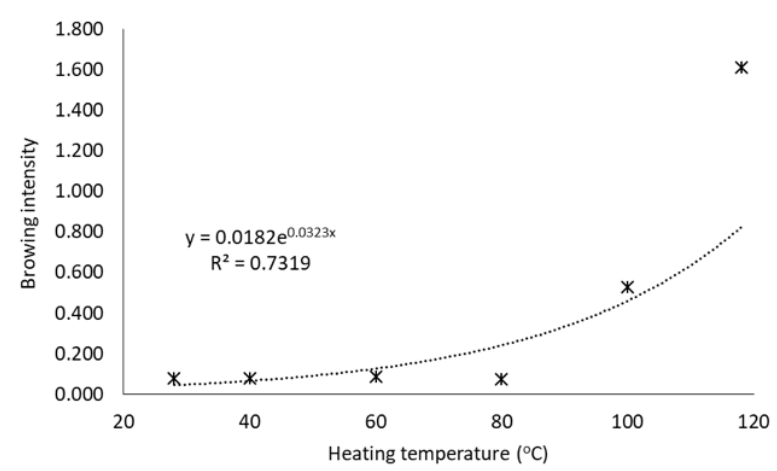

(d)

Figure 3. The relationship between heating temperature and browning intensity with addition of lysine: (a) $0 \mathrm{mM}$ (no addition), (b) $0.25 \mathrm{mM}$, (c) $0.5 \mathrm{mM}$, and (d) $0.75 \mathrm{mM}$. 
Table 2. Regression equation of the relationship between DPPH and heating temperature with various concentration of lysine addition

\begin{tabular}{cccc}
\hline Concentration of lysine addition $(\mathrm{mM})$ & Regression equation & $\mathrm{R}^{2}$ & Range of heating temperature $\left({ }^{\circ} \mathrm{C}\right)$ \\
\hline 0 & $D P P H=0.4594 \times e^{0.0321(T)}$ & 0.5996 & $28-118$ \\
0.25 & $D P P H=0.5977 \times e^{0.0307(T)}$ & 0.6601 & $28-118$ \\
0.5 & $D P P H=0.4687 \times e^{0.0307(T)}$ & 0.5224 & $28-118$ \\
0.75 & $D P P H=0.7662 \times e^{0.0261(T)}$ & 0.4433 & $28-118$ \\
\hline
\end{tabular}

$$
\Delta_{D P P H}=\frac{\left(D P P H_{T 118}-D P P H_{T 0}\right)}{D P P H_{T 0}}
$$

Furthermore, the results of multiple linear regression show that the combination of lysine concentration added to sap and heating temperature revealed less significant correlation to DPPH scavenging activity. The multiple $\mathrm{R}$ (coefficient of correlation) was 0.7335 while the adjusted $\mathrm{R}^{2}$ was 0.494 .

Table 3. $\Delta_{\text {DPPH }}$ of coconut sap with different lysine concentration

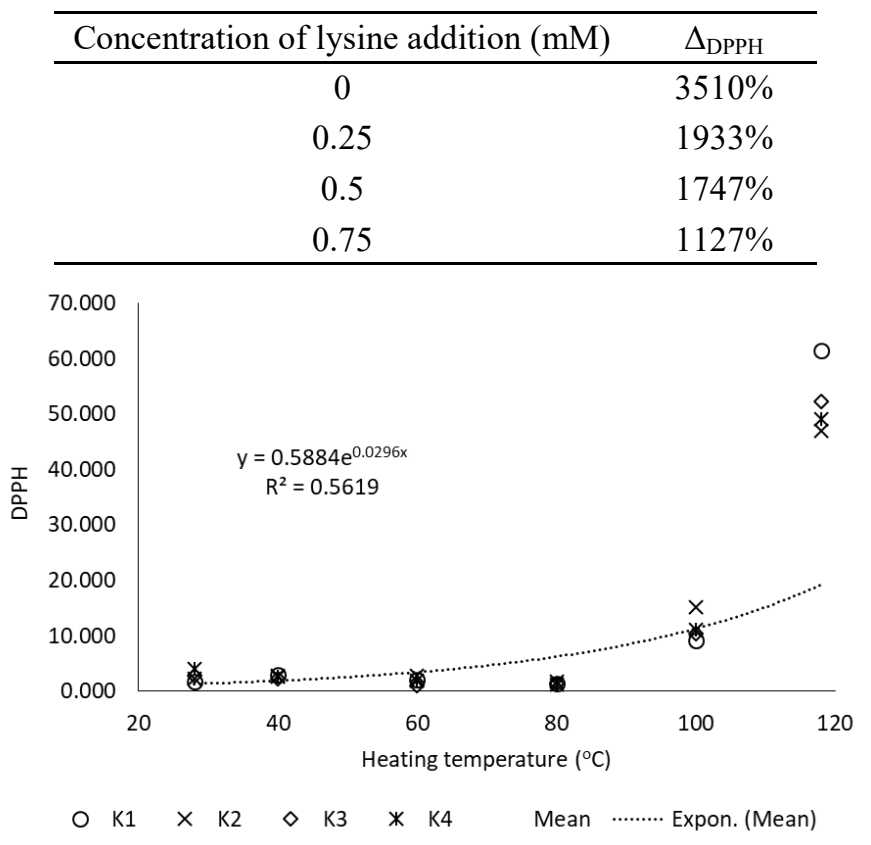

Figure 4. The relationship between heating temperature and DPPH scavenging activity with various concentration of lysine addition.

\subsection{Regression analysis of chelating activity}

The changes of mean chelating activity $(C A)$ of coconut sap during heating process followed a quadratic regression function with $\mathrm{R}^{2}$ value of 0.94 and in the range of $28-100^{\circ} \mathrm{C}$ heating temperature. The regression formula of this correlation was $C A=-0.0019 \times T^{2}+$
$0.2069 \times T+2.9159$, as seen in Figure 5. The coefficient value of $T^{2}$ is negative which indicates that the chelating activity increased at the beginning step of heating until reached a maximum value and then decreased until the end of the heating process. The effect of concentration of lysine addition to the chelating activity of coconut sap during heating also produced changes of chelating activity which followed a quadratic regression curve (Table 4).

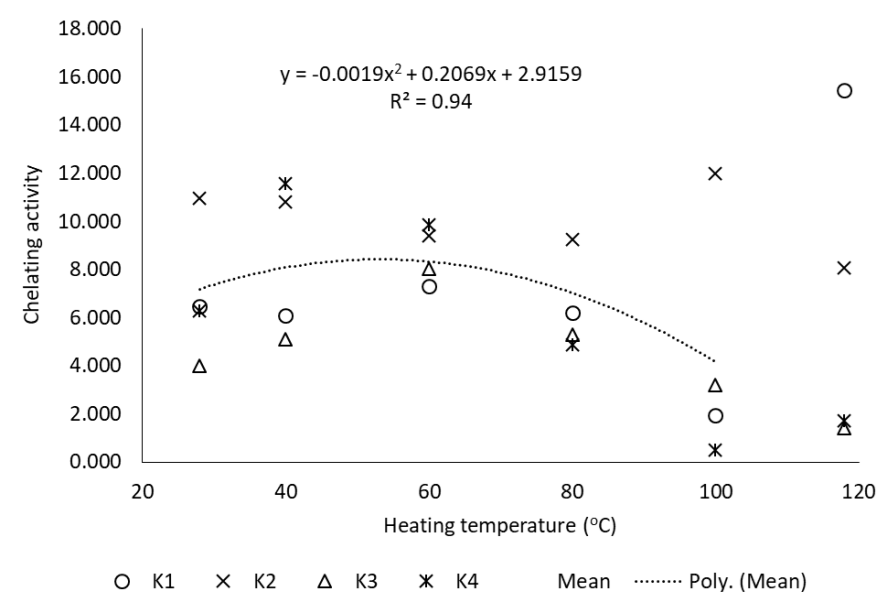

Figure 5. The relationship between heating temperature and chelating activity with various concentration of lysine addition.

\section{Conclusion}

The changes in the total phenolic content of coconut sap against temperature during heating process followed a logarithmic regression function. The correlation between total phenolic content and heating temperature was quite strong until the temperature reached $100^{\circ} \mathrm{C}$. Moreover, the changes in both browning intensity and DPPH scavenging activity of coconut sap against heating temperature followed an exponential regression. A quadratic regression function can represent the relationship between the chelating activity of coconut sap and heating temperature since the correlation of

Table 2. Regression equation of the relationship between DPPH and heating temperature with various concentration of lysine addition

\begin{tabular}{cccc}
\hline Concentration of lysine addition $(\mathrm{mM})$ & Regression equation & $\mathrm{R}^{2}$ & Range of heating temperature $\left({ }^{\circ} \mathrm{C}\right)$ \\
\hline 0 & $C A=-0.0034 \times T^{2}+0.4118 \times T-4.9412$ & 0.9976 & $40-100$ \\
0.25 & $C A=0.0017 \times T^{2}-0.2188 \times T+16.14$ & 0.8235 & $28-100$ \\
0.5 & $C A=-0.0019 \times T^{2}+0.2414 \times T-1.1148$ & 0.8431 & $28-118$ \\
0.75 & $C A=-0.0044 \times T^{2}+0.4499 \times T-1.5287$ & 0.8747 & $28-100$ \\
\hline
\end{tabular}


those parameters was relatively strong in the temperature range of $28-100^{\circ} \mathrm{C}$.

\section{Conflict of Interest}

The authors declare no conflict of interest.

\section{Acknowledgments}

This work was funded by the Ministry of Research, Technology and Higher Education through Fundamental Research scheme in 2019 (Contract No. P/1780/ UN23/14/PN/2019) and was supported by Research and Community Service Institution, Jenderal Soedirman University, Indonesia.

\section{References}

Ajandouz, E.H., Tchiakpe, L.S., Ore, F.D., Benajiba, A. and Puigserver, A. (2001). Effects of $\mathrm{pH}$ on caramelization and Maillard reaction kinetics in fructose-lysine model systems. Journal of Food Science, 66(7), 926-931. https://doi.org/10.1111/ j.1365-2621.2001.tb08213.x

Asikin, Y., Kamiya, A., Mizu, M., Takara, K., Tamaki, H. and Wada, K. (2014). Changes in the physicochemical characteristics, including flavour components and Maillard reaction products, of noncentrifugal cane brown sugar during storage. Food Chemistry, 149, 170-177. https://doi.org/10.1016/ j.foodchem.2013.10.089

Borse, B.B., Rao, L.J.M., Ramalakshmi, K. and Raghavan, B. (2007). Chemical composition of volatiles from coconut sap (neera) and effect of processing. Food Chemistry, 101(3), 877-880. https://doi.org/10.1016/j.foodchem.2006.02.026

Carciochi, R.A., Dimitrov, K. and D'Alessandro, L.G. (2016). Effect of malting conditions on phenolic content, Maillard reaction products formation, and antioxidant activity of quinoa seeds. Journal of Food Science and Technology, 53(11), 3978-3985. https:// doi.org/10.1007/s13197-016-2393-7

Hariharan, B., Singaravadivel, K. and Alagusundaram, K. (2014). Effect of food grade preservatives on the physicochemical and microbiological properties of coconut toddy during fermentation. Journal of Nutrition and Food Sciences, 4(5), 1-5. https:// doi.org/10.4172/2155-9600.1000299

Ho, C. W., Wan Aida, W.M., Maskat, M.Y. and Osman, H. (2008). Effect of thermal processing of palm sap on the physicochemical composition of traditional sugar. Pakistan Journal of Biological Sciences, 11 (7), 989-995. doi: https://doi.org/10.3923/ pjbs.2008.989.995
Karseno, Erminawati, Yanto, T., Setyowati, R. and Haryanti, P. (2018). Effect of $\mathrm{pH}$ and temperature on browning intensity of coconut sugar and its antioxidant activity. Food Research, 2(1), 32-38. https://doi.org/10.26656/fr.2017.2(1).175

Kim, J. (2013). Antioxidant activity of Maillard reaction products derived from aqueous and ethanolic glucose -glycine and its oligomer solutions. Food Science and Biotechnology, 22(1), 39-46. https:// doi.org/10.1007/s10068-013-0006-z

Nagai T., Kai, N., Tanoue, Y. and Suzuki, N. (2018). Chemical properties of commercially available honey species and the functional properties of caramelization and Maillard reaction products derived from these honey species. Journal of Food Science and Technology, 55(2), 586-597. https:// doi.org/10.1007/s13197-017-2968-y

Payet, B., Sing, A.S.C. and Smadja, J. (2005). Assessment of antioxidant activity of cane brown sugars by ABTS and DPPH radical scavenging assays: determination of their polyphenolic and volatile constituents. Journal of Agricultural and Food Chemistry, 53(26), 10074-10079. https:// doi.org/10.1021/jf0517703

Wijewickreme, A.N., Krejpcio, Z. and Kitts, D.D. (1999). Hydroxyl scavenging activity of glucose, fructose, and ribose-lysine model Maillard Products. Journal of Food Science, 64(3), 457-461. https:// doi.org/10.1111/j.1365-2621.1999.tb15062.x

Yan, F., Yu, X. and Jing, Y. (2018). Optimized preparation, characterization, and antioxidant activity of chitooligosaccharide-glycine Maillard reaction products. Journal of Food Science and Technology, 55(2), 712-720. https://doi.org/10.1007/ s13197-017-2982-0 